\title{
Valor nutritivo do capim-xaraés em três intensidades luminosas
}

[Nutritive value of xaraés palisade grass in three light intensities]

J.S. Barros ${ }^{1}$, P.R.L. Meirelles ${ }^{2}$, V.C. Gomes ${ }^{1}$, C.M. Pariz ${ }^{2}$, D.F. Fachiolli ${ }^{1}$,

\author{
${ }^{1}$ Programa de pós-graduação - Universidade Estadual Paulista - Botucatu, SP \\ ${ }^{2}$ Universidade Estadual Paulista - Botucatu, SP \\ ${ }^{3}$ Faculdade Anclivepa - São Paulo, SP
}

\begin{abstract}
RESUMO
Este trabalho teve como objetivo avaliar o valor nutritivo e a força de cisalhamento da cultivar de Urochloa brizantha (syn Brachiaria brizantha) cv Xaraés submetida a três intensidades luminosas e quatro cortes. O experimento foi conduzido na FMVZ - Unesp de Botucatu, com delineamento experimental em blocos ao acaso, sendo os tratamentos: luminosidade natural, redução de $30 \%$ e $60 \%$ de luz, com quatro cortes e três repetições. As análises realizadas foram: composição bromatológica, digestibilidade e a força de cisalhamento. Não houve diferença na digestibilidade entre os tratamentos em nenhum dos cortes, mas a qualidade forrageira foi influenciada pelos níveis de intensidade de luz, tendo o tratamento com $60 \%$ de redução de luminosidade apresentado maiores concentrações de proteína bruta e cinzas, menores teores de fibra em detergente neutro, hemicelulose, celulose e força de cisalhamento. Em relação aos cortes estudados, o primeiro teve o menor intervalo de corte e produziu forragem com qualidade superior em comparação ao último, pois obteve menor teor de fibra em detergente ácido, lignina, hemicelulose, celulose e consequente menor força de cisalhamento. Portanto, a redução de $60 \%$ de luminosidade é benéfica à qualidade e à força de cisalhamento da cultivar Xaraés.
\end{abstract}

Palavras-chave: digestibilidade, força de cisalhamento, sombreamento artificial, Urochloa brizantha

\begin{abstract}
This study aimed to evaluate the nutritive value and shear strength of the Xaraés grass (Urochloa brizantha) under the three intensities of light and four cuts. The experiment was conducted at FMVZ UNESP, Botucatu, with a randomized block design, with the following treatments: natural luminosity, $30 \%$ and $60 \%$ light reduction, with four cuts and three replications. The analyzes were bromatological composition, digestibility, and shearing strength. There was no difference in digestibility between the treatments in any of the cuts, forage quality was influenced by the light intensity levels, and the treatment with $60 \%$ of light reduction produced higher concentrations of crude protein and ash, lower levels of neutral detergent fiber, hemicellulose, cellulose and shear strength. According to the studied cuts, the first one had the lowest cut interval and produced superior forage compared with the last one, as it obtained lower fiber content in acid detergent, lignin, hemicellulose, cellulose and consequent lower shear force. Therefore, the reduction of $60 \%$ of luminosity is beneficial to the quality and shear force of the Xaraés palisade grass.
\end{abstract}

Keywords: artificial shading, digestibility, palisade grass, shearing strength

\section{INTRODUÇÃO}

A produção de bovinos no Brasil tem nas pastagens tropicais a base da sua alimentação devido à disponibilidade de área, ao baixo custo

Recebido em 22 de maio de 2018

Aceito em 11 de dezembro de 2018

E-mail: juliana.1234barros@gmail.com por quilograma de massa seca de forragem produzida, à diversidade de espécies forrageiras existentes e ao potencial de produção. Entre as espécies forrageiras utilizadas, as do gênero Urochloa apresentam destaque por sua capacidade de se adaptar às variadas condições de clima e solo. 
Os fatores climáticos, a água e os nutrientes são variáveis capazes de alterar a produção e a qualidade da forrageira (Gobbi et al., 2009). Entre as variações microclimáticas, as modificações no ambiente luminoso (sombreamento) têm merecido grande destaque por influenciarem as características morfológicas das forrageiras (Paciullo et al., 2011). Nesse contexto, os sistemas de integração de árvores, pastagens e animais com a finalidade de obter produtos desses três componentes é uma alternativa de manejo que apresenta bons resultados, pois reduz os efeitos das condições climáticas estressantes para os animais, com consequente aumento da produtividade $\mathrm{e}$ biodiversidade da área (Nicodemo et al., 2004).

Embora a utilização desses sistemas integrados seja uma alternativa sustentável e apresente resultados satisfatórios na produção animal, devem-se selecionar espécies forrageiras que se desenvolvam bem sob o sombreamento, bem como escolher espécies com boa capacidade produtiva, adaptadas ao manejo e às condições edafoclimáticas da região onde serão implantadas. Nesse aspecto, segundo Santana (2013), a utilização de sombreamento artificial para estudos de produção forrageira sob luminosidade reduzida é uma ferramenta importante para elucidar o comportamento das plantas previamente à sua utilização nas integrações com lavoura e componentes arbóreos. Diante do exposto, o objetivo do estudo foi avaliar o valor nutritivo e a força de cisalhamento da Urochloa brizantha (syn Brachiaria brizantha) cultivar Xaraés submetida a três intensidades luminosas (natural e reduzida em 30 e $60 \%$ com sombreamento artificial) em quatro cortes.

\section{MATERIAL E MÉTODOS}

O experimento foi conduzido na Faculdade de Medicina Veterinária e Zootecnia, Unesp Câmpus de Botucatu, no Setor de Forragicultura da Fazenda Experimental Lageado de Ensino, Pesquisa e Produção. O local situa-se a $22^{\circ} 51^{\prime} 01^{\prime \prime}$ de latitude sul e 48 $25^{\prime} 27^{\prime \prime}$ de longitude oeste, e possui $800 \mathrm{~m}$ de altitude. De acordo com a classificação de Köeppen, o clima predominante na região é do tipo Cwa (tropical de altitude), com inverno seco e verão quente e chuvoso. O período experimental em campo foi de dois anos (11/2014 a 11/2016) entre implantação, uniformização e coletas.

Foram coletados os dados climáticos referentes ao período experimental na estação meteorológica do Departamento de Recursos Naturais da Faculdade de Ciências Agronômicas da Unesp - Câmpus de Botucatu, situada cerca de 900 metros da área do experimento. Os dados climáticos da região (precipitação pluvial, temperaturas mínima, média e máxima) referentes a esse período estão apresentados na Fig. 1.

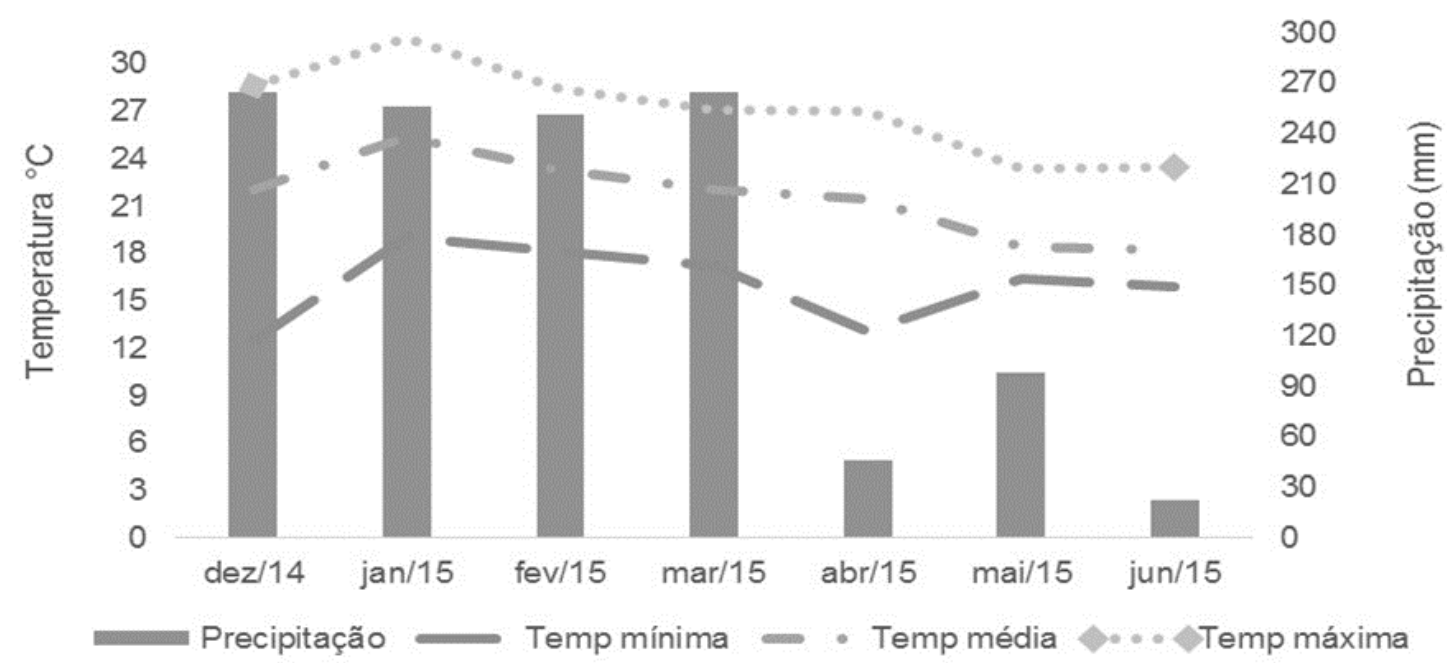

Figura 1. Dados climáticos (precipitação pluvial, temperaturas mínima, média e máxima) referentes ao período experimental; estação meteorológica FCA - Unesp, Câmpus Botucatu/SP (2015). 
O solo da área experimental é classificado como Latossolo Vermelho Distrófico (Sistema..., 2009). Antes do início do experimento, procedeu-se à amostragem do solo e coletou-se amostra na profundidade de $0-20 \mathrm{~cm}$. Os resultados foram: $\mathrm{pH}(\mathrm{CaCl}): 5,55$; matéria orgânica: $30,5 \mathrm{~g} / \mathrm{dm}^{3} ; \mathrm{P}$ (resina): $14 \mathrm{mg} / \mathrm{dm}^{3} ; \mathrm{S}$ : $8,5 \mathrm{mg} / \mathrm{dm}^{3}$ e V: $71 \%$. Os teores de Ca, $\mathrm{Mg}$ e K foram 38,17 e $1,3 \mathrm{mmolc} / \mathrm{dm}^{3}$, respectivamente. A capacidade de troca de cátions (CTC) foi de $79,5 \mathrm{mmolc} / \mathrm{dm}^{3}$. A adubação foi realizada na proporção de $200 \mathrm{~kg}$ do fertilizante formulado 20 00-20 (NPK) por hectare, para atender à exigência da planta.

O delineamento experimental adotado foi em blocos ao acaso, com quatro cortes e três repetições. Foi utilizada a $U$. brizantha cv. Xaraés e três níveis de luminosidade (pleno sol e redução de 30 e $60 \%$ da luminosidade); cada parcela possuía medidas de 4 x $5 \mathrm{~m}\left(20 \mathrm{~m}^{2}\right)$, com área útil para as avaliações de $12 \mathrm{~m}^{2}(3 \mathrm{x} 4 \mathrm{~m})$. A área experimental mantida sob condições de pleno sol já se encontrava implantada desde outubro/2013 (na densidade de $5 \mathrm{~kg} / \mathrm{ha}$ de sementes puras e viáveis), em linhas com espaçamento de $25 \mathrm{~cm}$ (16 linhas de $5 \mathrm{~m} /$ parcela), e estava sendo mantida por meio de adubação e cortes periódicos das forrageiras. Realizou-se um corte de uniformização (11/12/2014) com auxílio de um aparador de cerca-viva HS 45 STIHL $^{\circledR}$, estando todas as parcelas a $15 \mathrm{~cm}$ de altura do solo. Logo após a uniformização, efetuou-se a cobertura das parcelas com o sombreamento artificial para redução da luminosidade, utilizando-se telas de "nylon" pretas, comercialmente conhecidas como sombrites, de 30 e $60 \%$ de interceptação da radiação solar incidente, conforme especificações do fabricante das telas Chromatinet (Polysack Plastic Industries $\left.{ }^{\circledR}\right)$.

Foram realizados quatro cortes para avaliação dos tratamentos; a data do primeiro e dos demais cortes foi determinada quando as parcelas de Xaraés atingiram $95 \%$ de interceptação luminosa. As medições foram realizadas em diferentes pontos representativos de cada parcela, acima e abaixo do dossel, para cálculo da interceptação, utilizando-se um medidor de radiação fotossinteticamente ativa (RFA) AccuPAR model LP-80 PAR/LAI (Decagon devices ${ }^{\circledR}$ ). A interceptação luminosa (IL) foi determinada de acordo com Carnevalli (2003):
$\mathrm{IL}=($ RFA abaixo do dossel/RFA acima do dossel forrageiro) $x$ 100. Esse procedimento foi realizado em intervalos de três dias, até se atingir a interceptação luminosa preconizada. Nesse momento, foi realizado corte, no nível do solo, de toda forragem presente no interior de uma moldura com medidas de $0,5 \times 0,5 \mathrm{~m}\left(0,25 \mathrm{~m}^{2}\right) \mathrm{em}$ cada parcela. A forragem cortada do interior da moldura foi pesada e homogeneizada.

Após cada coleta das amostras, foi realizado um novo corte de uniformização das parcelas. Nessa ocasião, as unidades experimentais receberam adubação com nitrogênio e potássio, utilizandose fertilizante formulado 20-00-20 (NPK) na mesma proporção empregada após corte de uniformização $(200 \mathrm{~kg} / \mathrm{ha})$.

A amostra coletada foi seca em estufa com circulação de ar forçada a $65^{\circ} \mathrm{C}$, por 48 horas, depois foi processada em moinho tipo Willey em peneira com crivos de $1 \mathrm{~mm}$, retornando à estufa por 24 horas a $105^{\circ} \mathrm{C}$ para determinação de matéria seca (MS) e determinação laboratorial bromatológica, no Laboratório de Bromatologia da Faculdade de Medicina Veterinária e Zootecnia (FMVZ/Unesp), Campus de Botucatu. As análises dos teores de proteína bruta (PB) e celulose (CEL) foram realizadas segundo metodologia descria por AOAC (Official..., 1995). A determinação dos teores de fibra insolúvel em detergente neutro (FDN), fibra insolúvel em detergente ácido (FDA) e lignina (LIG) seguiu metodologia descrita por Van Soest et al. (1991). A hemicelulose (Hemicel) foi obtida por meio da diferença entre os teores de FDN e FDA, e as cinzas foram obtidas por meio de queima de amostras em mufla a $550^{\circ} \mathrm{C}$.

A digestibilidade in vitro da MS (DIVMS) foi realizada segundo técnicas descritas pelo Van Soest et al. (1991) no fermentador ruminal DAISY II (ANKOM® Technology Corp., Fairport, NY). Para isso, foi utilizado líquido ruminal (inóculo ruminal) de um bovino provido de cânula ruminal adaptado à dieta com forragem. A digestibilidade foi calculada pela seguinte fórmula: \% DIVMS = $100-(($ saquinho após digestão) - (saquinho vazio x branco)) $\div$ peso amostra $\mathrm{x} 100$.

Em cada corte, foram escolhidos ao acaso 10 perfilhos em cada parcela, e destes foi retirada uma folha plenamente expandida. Posteriormente, essas folhas foram levadas ao 
laboratório de Tecnologia dos Produtos Agropecuários, pertencente à Faculdade de Ciências Agronômicas - Unesp - Câmpus de Botucatu, para se determinar a força de cisalhamento por meio do texturômetro TA XTPlus Texture Analyser 2i, marca Stable Micro System (UK), equipado com conjunto de lâmina Warner-Bratzler (capacidade de $25 \mathrm{~kg}$ e velocidade do seccionador de $20 \mathrm{~cm} / \mathrm{min}$ ). O instrumento foi utilizado para medir a resistência das folhas ao corte (cisalhamento), conforme descrito por Hughes et al. (2000).

Todos os dados foram inicialmente testados quanto à normalidade com o teste de ShapiroWilk do procedimento UNIVARIATE do SAS (versão 9.4, SAS Inst.Inc., Cary, NC) e os resultados indicaram que todos os dados foram distribuídos normalmente $(\mathrm{W}>0,90)$. Os dados para todas as variáveis foram analisados utilizando-se o procedimento PROC MIXED do SAS e aproximação Satterthwaite para se determinar o denominador e os graus de liberdade para os testes de efeitos fixos. Tratamentos, cortes e todas as interações resultantes foram considerados efeitos fixos. Os dados foram analisados utilizando-se bloco como variável aleatória. $\mathrm{O}$ modelo estatístico utilizado para a análise das variáveis de produção de forragem e composição continha os efeitos dos tratamentos, e o termo especificado para a repetição foi o corte; a estrutura de covariância utilizada para todas as repetições foi a simetria composta (SC), que forneceu o melhor ajuste de acordo com o critério de informação Akaike. Os resultados são relatados como quadrados mínimos e separados usando-se a opção de probabilidade de diferenças (PDIFF). Os efeitos foram considerados como estatisticamente significativos para $\mathrm{P} \leq 0,05$.

\section{RESULTADOS E DISCUSSÃO}

Na composição bromatólogica do capim-xaraés, não houve diferença estatística em relação aos tratamentos (redução de luminosidade) sobre a matéria seca, porém verificou-se diferença entre os cortes, tendo o quarto corte os maiores teores de matéria seca em relação aos demais cortes (Tab. 2). Esse resultado pode ser explicado pelo intervalo entre os cortes, que foi de 45 dias para esse tratamento, sendo maior que os demais. De acordo com Costa et al. (2007), à medida que se prolonga o intervalo de cortes, o teor de matéria seca da forragem tende a aumentar. A planta, quando nova, apresenta maiores teores de água; portanto, quanto mais próxima estiver da sua maturidade fisiológica, mais esse teor é reduzido.

Verificou-se ainda que, em relação aos níveis de luminosidade, o tratamento com $60 \%$ de redução de luz teve maior produção de massa seca total e também maior taxa de acúmulo de massa seca (mostrando que foi o mais produtivo no período experimental, independentemente do intervalo de cortes).

Outro fator que contribuiu para os resultados de matéria seca foi a precipitação ocorrida durante o período experimental. O primeiro corte foi realizado no mês de janeiro, quando a quantidade de chuva foi muito superior aos meses de abril e junho, época em que foi realizado o quarto corte (Tab. 1 e Fig. 1). Magalhães (2010) explica que, em experimentos em que se observam maiores teores de água, os teores de matéria seca tendem a ser menores, em razão da maior disponibilidade de água a ser absorvida do solo e, consequentemente, há maiores teores de água nas células, resultando em menores teores de matéria seca. O nível de sombreamento e o intervalo entre cortes afetaram os teores de PB (Tab. 2). O tratamento com $60 \%$ de redução de luminosidade resultou em maiores quantidades de $\mathrm{PB}$ em todos os cortes. De modo geral, estudos comprovam aumentos relativos nos teores de proteína bruta da forragem sob sombreamento em comparação ao sol pleno (Barro et al., 2008).

Tabela 1. Datas e intervalos de cortes do Urochloa brizantha cv. Xaraés sob três níveis de intensidade luminosa

\begin{tabular}{ccccccccc}
\hline \multirow{2}{*}{ Tratamentos } & \multicolumn{4}{c}{ Datas de cortes } & \multicolumn{4}{c}{ Intervalos de cortes (dias) } \\
\cline { 2 - 8 } & $1^{\circ}$ & $2^{\circ}$ & $3^{\circ}$ & $4^{\circ}$ & $1^{\circ}$ & $2^{\circ}$ & $3^{\circ}$ & $4^{\circ}$ \\
\hline $0 \%$ & $05 / 01 / 15$ & $10 / 02 / 15$ & $06 / 03 / 15$ & $11 / 04 / 15$ & 25 & 36 & 25 & 36 \\
$30 \%$ & $05 / 01 / 15$ & $10 / 02 / 15$ & $06 / 03 / 15$ & $17 / 04 / 15$ & 25 & 36 & 25 & 42 \\
$60 \%$ & $15 / 01 / 15$ & $06 / 03 / 15$ & $04 / 05 / 15$ & $15 / 06 / 15$ & 35 & 51 & 59 & 42 \\
\hline
\end{tabular}

0\% - cultivar Xaraés sob sol pleno; $30 \%$ - cultivar Xaraés sob redução de 30\% intensidade luminosa; $60 \%$ cultivar Xaraés sob redução de $60 \%$ intensidade luminosa. 
Valor nutritivo do...

Tabela 2. Valor nutritivo dos cortes de $U$. brizantha cv. Xaraés sob diferentes níveis de intensidades luminosas

\begin{tabular}{|c|c|c|c|c|c|c|c|c|c|}
\hline \multirow{2}{*}{$\begin{array}{c}\text { Variáveis } \\
(\%)\end{array}$} & \multirow{2}{*}{ Trat } & \multicolumn{3}{|c|}{ Cortes } & \multirow[b]{2}{*}{4} & \multirow[t]{2}{*}{$\mathrm{EMP}^{2}$} & \multicolumn{2}{|r|}{$\mathrm{P}$} & \multirow[b]{2}{*}{$\mathrm{T}^{*} \mathrm{C}$} \\
\hline & & 1 & 2 & 3 & & & Trat & Corte & \\
\hline \multirow{3}{*}{ MS } & $0 \%$ & $22,31 \mathrm{~b}$ & $22,16 b$ & $22,93 \mathrm{~b}$ & $24,85 \mathrm{a}$ & 0,2951 & 0,2792 & $<0,0001$ & 0,0550 \\
\hline & $30 \%$ & $21,96 \mathrm{~b}$ & $21,86 \mathrm{~b}$ & 23,16 a & $24,55 \mathrm{a}$ & & & & \\
\hline & $60 \%$ & $22,52 \mathrm{~b}$ & $21,94 \mathrm{~b}$ & $22,92 \mathrm{~b}$ & $24,85 \mathrm{a}$ & & & & \\
\hline \multirow{3}{*}{ PB } & $0 \%$ & $4,50 \mathrm{Bb}$ & $5,13 \mathrm{Cb}$ & $5,08 \mathrm{Bb}$ & $6,27 \mathrm{Ba}$ & 0,7432 & 0,0016 & $<0,0001$ & 0,0012 \\
\hline & $30 \%$ & $6,77 \mathrm{ABb}$ & $6,90 \mathrm{Bb}$ & $8,35 \mathrm{Aa}$ & 7,99 $\mathrm{Ba}$ & & & & \\
\hline & $60 \%$ & $7,55 \mathrm{Ab}$ & $9,52 \mathrm{Aa}$ & $9,33 \mathrm{Aa}$ & $10,24 \mathrm{Aa}$ & & & & \\
\hline \multirow{3}{*}{ FDN } & $0 \%$ & $75,08 \mathrm{Aa}$ & $75,44 \mathrm{Aa}$ & $73,19 \mathrm{Ab}$ & $73,21 \mathrm{Aab}$ & 1,06 & 0,0297 & 0,0226 & 0,0705 \\
\hline & $30 \%$ & $73,50 \mathrm{Aa}$ & 72,99 ABa & $70,28 \mathrm{Bb}$ & $73,14 \mathrm{Aa}$ & & & & \\
\hline & $60 \%$ & $70,61 \mathrm{Ba}$ & $71,52 \mathrm{Ba}$ & $71,88 \mathrm{ABa}$ & $71,03 \mathrm{Ba}$ & & & & \\
\hline \multirow{3}{*}{ FDA } & $0 \%$ & $35,47 \mathrm{~b}$ & $35,48 \mathrm{~b}$ & $35,56 \mathrm{~b}$ & $37,36 \mathrm{a}$ & 1,38 & 0,1431 & 0,0004 & 0,0114 \\
\hline & $30 \%$ & $34,87 \mathrm{~b}$ & $34,13 \mathrm{~b}$ & $36,91 \mathrm{a}$ & $36,59 \mathrm{a}$ & & & & \\
\hline & $60 \%$ & $34,74 \mathrm{~b}$ & $35,98 \mathrm{a}$ & $36,83 \mathrm{a}$ & $36,99 \mathrm{a}$ & & & & \\
\hline \multirow{3}{*}{ Celulose } & $0 \%$ & $33,03 \mathrm{Ab}$ & $34,38 \mathrm{Aa}$ & $34,47 \mathrm{Aa}$ & $35,11 \mathrm{Aa}$ & 0,60 & 0,0460 & $<0,0001$ & $<0,0001$ \\
\hline & $30 \%$ & $30,83 \mathrm{Bb}$ & $34,08 \mathrm{Aa}$ & $32,02 \mathrm{Bb}$ & $33,60 \mathrm{Ba}$ & & & & \\
\hline & $60 \%$ & $29,68 \mathrm{Bb}$ & $30,90 \mathrm{Bb}$ & $32,68 \mathrm{Ba}$ & $33,20 \mathrm{Ba}$ & & & & \\
\hline \multirow{3}{*}{ Hemicel. } & $0 \%$ & $35,85 \mathrm{Ab}$ & $38,90 \mathrm{Aa}$ & $37,63 \mathrm{Aa}$ & $38,61 \mathrm{Aa}$ & 0,70 & 0,0344 & $<0,0001$ & 0,0002 \\
\hline & $30 \%$ & $36,55 \mathrm{Ab}$ & $38,86 \mathrm{Aa}$ & $33,37 \mathrm{Bb}$ & $38,63 \mathrm{Aa}$ & & & & \\
\hline & $60 \%$ & $34,05 \mathrm{Bb}$ & $34,04 \mathrm{Bb}$ & $35,75 \mathrm{Ba}$ & $35,87 \mathrm{Ba}$ & & & & \\
\hline \multirow{3}{*}{ Lignina } & $0 \%$ & $2,53 \mathrm{~b}$ & 3,21 a & $3,44 \mathrm{a}$ & $3,55 \mathrm{a}$ & 0,67 & 0,6843 & 0,0038 & 0,4399 \\
\hline & $30 \%$ & $2,04 \mathrm{~b}$ & $2,23 \mathrm{~b}$ & $2,45 \mathrm{~b}$ & 3,98 a & & & & \\
\hline & $60 \%$ & $2,06 \mathrm{~b}$ & $2,50 \mathrm{ab}$ & $3,35 \mathrm{a}$ & $3,78 \mathrm{a}$ & & & & \\
\hline \multirow{3}{*}{ Cinzas } & $0 \%$ & $6,30 \mathrm{Ba}$ & $6,84 \mathrm{Ba}$ & $5,19 \mathrm{Bb}$ & $5,50 \mathrm{Bb}$ & 0,36 & 0,0198 & 0,0004 & 0,0767 \\
\hline & $30 \%$ & 7,00 Aa & 7,71 Aba & 7,25 Aa & $5,90 \mathrm{Bb}$ & & & & \\
\hline & $60 \%$ & 7,79 Аа & $8,17 \mathrm{Aa}$ & 7,80 Aa & $6,92 \mathrm{Ab}$ & & & & \\
\hline \multirow{3}{*}{ Digest. } & $0 \%$ & 75,00 & 74,90 & 75,39 & 74,87 & 0,50 & 0,1360 & 0,9738 & 0,5129 \\
\hline & $30 \%$ & 74,29 & 75,02 & 74,64 & 74,03 & & & & \\
\hline & $60 \%$ & 74,09 & 74,85 & 74,47 & 74,52 & & & & \\
\hline
\end{tabular}

${ }^{1}$ Valores corrigidos para $100 \%$ de matéria seca. ${ }^{2} \mathrm{EMP}$ - Erro médio padrão.

Médias seguidas da mesma letra maiúscula na coluna não diferem entre si para tratamento pelo teste $\mathrm{t}$ de Student a $\mathrm{P}<0,05$. Médias seguidas da mesma letra minúscula na linha não diferem entre si para cortes pelo teste $\mathrm{t}$ de Student a $\mathrm{P}<0,05$.

MS - matéria seca; PB - proteína bruta; FDN - fibra em detergente neutro; FDA - fibra em detergente ácido; Hemicel. - hemicelulose; Digest. - digestibilidade in situ.

O intervalo de corte indicou a redução de PB com o aumento do intervalo. Essa redução de PB com o avanço da maturidade das plantas é um fato amplamente relatado na literatura (Aguiar et al., 2000; França et al., 2007; Verdecia et al., 2008; Silva, 2009) e deve-se, provavelmente, ao efeito de diluição do conteúdo de PB na matéria seca produzida e acumulada (Andrade et al., 2004). Neste trabalho, os teores de PB estiveram acima dos $7 \%$ nos tratamentos de 30 e $60 \%$ de sombreamento. Segundo o NRC (Nutrient..., 1984), esse limite de $7 \%$ se aplica a bovinos adultos, aumentando-se para $11 \%$ a exigência mínima de PB quando se trata de animais jovens. Esses autores afirmam ainda que teores de PB abaixo desses limites ocasionam queda na ingestão de massa seca pelos animais, devido à carência de nitrogênio aos microrganismos ruminais. Tais resultados, aliados aos observados nos teores de fibra e digestibilidade, indicam que o sombreamento promove alterações benéficas na composição nutricional das plantas e resulta em uma forragem com melhor valor nutritivo.

O material cortado no tratamento com $60 \%$ de redução de luz foi o que apresentou maior porcentagem de cinzas $(\mathrm{P}=0,0198)$, o quarto corte apresentou maior teor de cinzas em comparação ao primeiro corte, resultado obtido principalmente pelo intervalo entre corte (Tab. 1 e 2). O mesmo comportamento dos dados de FDA, lignina e FDN observado neste 
experimento entre os tratamentos (Tab. 2) foi encontrado por Paciullo et al. (2007), que, ao avaliarem o valor nutritivo da Urochloa decumbens em um sistema silvipastoril, constataram que a condição de luminosidade não influenciou nos teores de FDA $(36,4 \%$ em pleno sol e $38 \%$ em sombreamento) e de lignina (7,3\% em pleno sol e 7,2\% em sombreamento). Esses autores, no entanto, observaram efeito $(\mathrm{P}<0,05)$ isolado do ambiente luminoso nos teores de FDN, cujos valores foram menores sob a copa das árvores que em condições de luz solar plena $(75,9 \%$ em pleno sol e $73,1 \%$ em sombreamento).

Os valores de lignina não apresentaram diferença significativa entre os tratamentos $(\mathrm{P}=0,6843)$. Segundo Casler (2001), as mudanças na composição da parede celular ocorrem principalmente devido ao aumento nos teores de lignina. A concentração de lignina e sua composição parecem regular geneticamente a variação da digestibilidade in vitro da matéria seca das culturas forrageiras. Já em relação aos cortes, houve variação nos teores de lignina $(\mathrm{P}=0,0038)$ : o primeiro corte mostrou menores valores nos três níveis de intensidades de luz, enquanto o último obteve os maiores valores. $\mathrm{O}$ que favoreceu esse resultado foi o intervalo entre os cortes. Balsalobre et al. (2001) relatam que as maiores mudanças que ocorrem na composição das plantas forrageiras são aquelas decorrentes de sua maturidade. A maioria das espécies forrageiras sofre crescente lignificação da parede celular e aumento da proporção de celulose, hemicelulose e FDA com o aumento da idade.

Por isso, o mesmo comportamento da lignina foi observado para a FDA, que também não mostrou diferença entre os níveis de sombreamento estudados $(\mathrm{P}=0,1431)$, mas apresentou diferença entre os cortes $(\mathrm{P}=0,0004)$, tendo o primeiro corte apresentado teores de FDA menores que o último, que possui intervalo de corte superior ao primeiro (Tab. 1 e 2). Os níveis de FDA, lignina, FDN e PB estão diretamente relacionados com a digestibilidade da planta, pois, com diminuição dos teores de fibra e lignina, aumenta a digestibilidade e a PB da forragem (Sales, 2015). Das variáveis citadas acima como componentes que interferem na digestibilidade, no presente estudo a porcentagem de sombreamento influenciou apenas os teores de FDN e PB e, assim como Cremon (2013), maiores valores de
PB e menores de FDN foram obtidos no tratamento de sombreamento $(60 \%$ de redução de luminosidade neste estudo), porém isso não contribuiu para aumento na digestibilidade, uma vez que a lignina e a FDA, que não tiveram efeito significativo (Tab. 2), possuem maior impacto na digestibilidade.

Para os resultados de digestibilidade do capimxaraés, não houve diferença significativa nos tratamentos $(\mathrm{P}=0,1360)$ nem nos cortes $(\mathrm{P}=0,9738)$. Os valores encontrados se assemelham aos reportados por outros autores, como Lopes (2013), que, ao estudar capimxaraés em quatro alturas de desfolha $(15,30,45$ e $60 \mathrm{~cm})$, encontrou valores médios de digestibilidade in vitro da matéria seca de 68, 72, 75 e $76 \%$. No presente experimento, a adaptação da planta à sombra, alongando folhas e colmo e aumentando o tamanho das células para torná-las mais específicas na captação de luz, pode ter sido compensada pelo maior número de perfilhamentos que ocorre nas plantas em pleno sol, não resultando em diferente disgestibilidade da planta inteira.

Os resultados de FDN ficaram dentro do esperado nos três níveis de luminosidade utilizados no experimento. De acordo com Rodrigues (2012), as gramíneas apresentam FDN raramente inferiores a $55 \%$, sendo normalmente observados valores de 65 a $75 \%$, dependendo do estádio vegetativo das plantas. Os maiores teores de FDN, em condições de alta luminosidade, podem ser associados à maior proporção de tecido esclerenquimático, cujas células apresentam paredes mais espessas do que em condições de sombreamento (Deinum et al., 1996).

De acordo com Sales (2015), a explicação para a diferença nos teores de FDN seria uma menor disponibilidade de fotoassimilados nas áreas sombreadas, o que causa uma redução do desenvolvimento da parede celular secundária, diminuindo, assim, a concentração dos constituintes da parede celular. Essa afirmação corrobora também os resultados de hemicelulose e celulose encontrados, em que o tratamento com $60 \%$ de redução de luminosidade apresentou menores valores para as duas variáveis.

Os valores de hemicelulose e celulose (Tab. 2) sofreram efeito significativo também entre os cortes $(\mathrm{P}<0,0001)$, tendo o último corte resultado 
em maiores teores em relação ao primeiro corte, pois, assim como a matéria seca, sofreu influência do aumento entre os intervalos de cortes (Tab. 1). Os valores de celulose observados no estudo variaram de 29,68 a $35,11 \%$, estando dentro do esperado. Conforme Van Soest et al. (1994), os teores desejáveis desse componente variam de 20 a $40 \%$ na matéria seca das plantas, para que se tenham baixos níveis dessa fração nas forrageiras. Já a hemicelulose variou de 33,37 a $38,63 \%$ e é a fração da parede celular mais facilmente digerida (Teixeira et al., 2010).

Segundo Patês et al. (2008), com o amadurecimento da planta, a produção de componentes potencialmente digeríveis (carboidratos solúveis, proteínas, minerais e outros conteúdos celulares) tende a decrescer. Ao mesmo tempo, as frações menos digeríveis, como celulose, hemicelulose e lignina, aumentam. Outra característica importante na determinação da qualidade da forragem é a força de cisalhamento, pois fornece medidas úteis para a caracterização física do tecido de folhas e é um indicador apropriado para identificar diferenças nutritivas e qualitativas entre espécies de Urochloa (Herrero et al., 2001). De acordo com Hughes et al. (2000), a força de cisalhamento tende a apresentar correlação positiva com características físicas da planta, ou seja, plantas com maior resistência apresentam maiores níveis de FDN, FDA, lignina e celulose. Isso corrobora os resultados deste experimento, em que houve efeito significativo entre os tratamentos ( $\mathrm{P}<0,0001)$, ocorrendo diminuição da força de cisalhamento com o aumento da porcentagem de sombra utilizada, acompanhando o comportamento dos componentes acima citados (Tab. 3). Comparando-se pleno sol e 60\% de redução de luminosidade, o de $60 \%$ obteve os menores teores de FDN, lignina e celulose e consequente menor força de cisalhamento (Tab. 2 e 3$)$.

Tabela 3. Força de cisalhamento dos cortes de $U$. brizantha cv. Xaraés sob níveis de intensidades luminosas

\begin{tabular}{|c|c|c|c|c|c|c|c|c|c|}
\hline \multirow{2}{*}{ Variáveis } & \multirow{2}{*}{ Trat } & \multicolumn{4}{|c|}{ Cortes } & \multirow{2}{*}{$\mathrm{EMP}^{2}$} & \multicolumn{3}{|c|}{$\mathrm{P}$} \\
\hline & & 1 & 2 & 3 & 4 & & Trat & Corte & $\mathrm{T} * \mathrm{C}$ \\
\hline \multirow{3}{*}{$\begin{array}{c}\text { F. Cisa } \\
\text { (kgf) }\end{array}$} & $0 \%$ & $12,05 \mathrm{Ab}$ & $12,11 \mathrm{Ab}$ & $13,33 \mathrm{Aa}$ & $13,44 \mathrm{Aa}$ & 0,2385 & $<0,0001$ & $<0,0001$ & $<0,0001$ \\
\hline & $30 \%$ & $10,19 \mathrm{Bb}$ & $10,20 \mathrm{Bb}$ & $11,72 \mathrm{Ba}$ & $11,80 \mathrm{Ba}$ & & & & \\
\hline & $0 \%$ & $12,05 \mathrm{Ab}$ & $12,11 \mathrm{Ab}$ & $13,33 \mathrm{Aa}$ & $13,44 \mathrm{Aa}$ & & & & \\
\hline
\end{tabular}

1Valores corrigidos para $100 \%$ de matéria seca. ${ }^{2} \mathrm{EMP}$ - Erro médio padrão.

Médias seguidas da mesma letra maiúscula na coluna não diferem entre si para tratamento pelo teste $\mathrm{t}$ de Student a $\mathrm{P}<0,05$.

Médias seguidas da mesma letra minúscula na linha não diferem entre si para cortes pelo teste $\mathrm{t}$ de Student a $\mathrm{P}<0,05$.

F.Cisa: força de cisalhamento.

A força de cisalhamento também apresentou diferença significativa entre os cortes $(\mathrm{P}<0,0001)$ (Tab. 3). Comparando-se o quarto com o primeiro corte, o quarto corte teve valores maiores de FDA, lignina e celulose e consequente maior força de cisalhamento (Tab. 2 e 3). A resistência ao cisalhamento é uma característica física que tem sido usada na caracterização qualitativa de capins do gênero Urochloa; é uma técnica barata e que fornece valores confiáveis (Valle et al., 2005).

\section{CONCLUSÃO}

O tratamento com $60 \%$ de redução de luminosidade produziu maior quantidade e melhor qualidade de forragem. A redução da intensidade luminosa refletiu em maior intervalo de cortes do que o pleno sol, o que prejudicou a qualidade da forragem no último corte. A cultivar Xaraés mostrou-se tolerante à redução de $60 \%$ de radiação solar.

\section{REFERÊNCIAS}

AGUIAR, R.S.; VASQUEZ, H.M.; SILVA, J.F.C. Produção e composição químico bromatológica do capim-furachão (Panicum repens L.) sob adubação e diferentes idades de corte. Rev. Bras. Zootec., v.29, p.325-333, 2000.

ANDRADE, C.M.; VALENTIM, J.F.; CARNEIRO, J.C.; VAZ, F.A. Crescimento de gramíneas e leguminosas forrageiras tropicais sob sombreamento. Pesqui. Agropecu. Bras., v.39, p.263-270, 2004. 
BALSALOBRE, M.A.A.; NUSSIO, L.G.; MARTHA JÚNIOR, G.B. Controle de perdas na produção de silagem de gramíneas tropicais. Em: SIMPÓSIO SOBRE MANEJO DA PASTAGEM, 2001, Piracicaba. Anais... Piracicaba: FEALQ, 2001. p.890-911. (Resumo)

BARRO, R.S.; SAIBRO, J.C.; MEDEIROS, R.B.; et al Rendimento de forragem e valor nutritivo de gramíneas anuais de estação fria submetidas a sombreamento por Pinus elliottii e ao sol pleno. Rev. Bras. Zootec., v.37, p.17211727, 2008.

CARNEVALLI, R.A. Dinâmica da rebrotação de pastos de capim-Mombaça submetidos a regimes de desfolhação intermitente. 2003. 136f. Tese (Doutorado em Agronomia) - Escola Superior de Agricultura "Luiz de Queiroz", Universidade de São Paulo, Piracicaba, SP.

CASLER, M.D. Breeding forage crops for increased nutritional value. Advances in Agronomy. Academic Press, San Diego, v.71, p.51-107, 2001.

COSTA, K.A.P.; OLIVEIRA, I.P.; FAQUIN, V. et al. Intervalo de corte na produção de massa seca e composição químico-bromatológica da Brachiaria brizantha cv. MG-5. Ciênc. Agrotec., v.31, p.1197-1202, 2007.

CREMON, T. Espaçamento entre faixas de árvores (Eucalyptus urophylla S.T.Blake) e suas interrelações com o acúmulo de forragem [Urochloa brizantha (Hochst. Ex A. Rich.) Stapf cv. Xaraés], microclima e bem-estar animal. 2013. 46f. Dissertação (Mestrado em Agronomia) - Universidade Federal da Grande Dourados, Dourados, Mato Grosso do Sul, MS.

DEINUM, B.; SULASTRI, R.D.; ZEINAB, M.H.J.; MAASSEN, A. Effects of light intensity on growth, anatomy and forage quality of two tropical grasses (Brachiaria brizantha and Panicum maximum var. Trichoglume). Neth. J. Agric. Sci., v.44, p.111-124, 1996.

FRANÇA, A.F.S.; BORJAS, A.L.R.; OLIVEIRA, E.R. et al. Parâmetros nutricionais do capim-tanzânia sob doses crescentes de nitrogênio em diferentes idades de corte. Cienc. Anim. Bras., v.8, p.695-703, 2007.
GOBBI, K.F.; GARCIA, R.; GARCEZ NETO, A.F. et al. Características morfológicas, estruturais e produtividade do capim-braquiária e do amendoim forrageiro submetidos ao sombreamento. Rev. Bras. Zootec., v.38, p.1645-1654, 2009.

HERRERO, M.; VALLE, C.B.; HUGHES, N.R.G.; et al Measurements of physical strength and their relationship to the chemical composition of four species of Brachiaria. Animal Feed Science and Technology, Amsterdam, p.149-158, 2001.

HUGHES, N.R.G.; VALLE, C.B.; SABATEL, V.; BOOCK, J. Shearing strength as and addition selection criterion for quality in Brachiaria pasture ecotypes. J. Agric. Sci., v.135, p.123-130, 2000.

LOPES, R.V. Estratégias de manejo em pastos de Brachiaria brizantha cv. Xaraés. 2013. Dissertação (Mestrado em Ciência Animal) Universidade Estadual de Londrina, Londrina, PR.

MAGALHÃES, J.A. Características morfogênicas e estruturais, produção de forragem e composição bromatológica de gramineas forrageiras sob irrigação $e$ adubação. 2010. Tese (Doutorado em Zootecnia) - Universidade Federal do Ceará, CE.

NICODEMO, M.L.F.; SILVA, V.P.; THIAGO L.R.L.S. et al. Sistemas silvipastoris introdução de árvores na pecuária do CentroOeste brasileiro. Embrapa Gado de Corte, Campo Grande-MS, Doc.146. p.17-20, 2004.

NUTRIENT requirements of beef cattle. 6.ed. Washington: National Academy of Sciences, 1984. 90p.

OFFICIAL methods of analysis. 15.ed. Washington: AOAC, 1995.

PACIULLO, D.S.C. The growth dynamics in Brachiaria species according to nitrogen dose and shade. Rev. Bras. Zootec., v.40, p.270-276, 2011.

PACIULLO, D.S.C.; CARVALHO, C.A.B.; AROEIRA, L.J.M. et al. Morfofisiologia e valor nutritivo do capim- braquiária sob sombreamento natural e a sol pleno. Pesqui. Agropecu. Bras., v.42, p.573-579, 2007. 
PATÊS, N.M.S.; PIRES, A.J.V.; CARVALHO, G.G.P. et al. Production and nutritive value of Tanzania grass fertilized with nitrogen and phosphorus. Rev. Bras. Zootec., v.37, p.19341939, 2008.

RODRIGUES, L.S. Consumo, digestibilidade e balanço de nitrogênio da torta de cupuaçu (Theobroma grandiflorum schun) proveniente da agroindústria cosmética. 2012. 57f. Dissertação (Mestrado em Ciência Animal) Universidade Federal do Pará, Belém, PA.

SALES, N.A. Ácumulo e qualidade da forragem Urochloa brizantha (hochst. Ex a. Rich.) Stapf cv. Xaraés com dois clones de eucalipto em sistema silvipastoril. 2015.61f. Dissertação (Mestrado em Agronomia) - Universidade Federal da Grande Dourados, Dourados, MS.

SANTANA, E.A.R. Desempenho e composição morfológica de duas cultivares de Brachiaria brizantha submetidas à intensidades luminosas. 2013. 63f. Dissertação (Mestrado em Zootecnia) - Universidade Estadual Paulista, Faculdade de Medicina Veterinária e Zootecnia, Botucatu, SP.

SILVA, M.W.R. Características estruturais, produtivas e bromatológicas das gramíneas tifton-85, marandu e tanzânia submetidas à irrigação. 2009. 54f. Dissertação (Mestrado em Zootecnia) - Universidade Estadual do Sudoeste da Bahia, Itapetininga, BA.
SISTEMA brasileiro de classificação de solos. Rio de Janeiro: Embrapa, 2009.

TEIXEIRA, V.I.; DUBEUX JÚNIOR, J.C.B.; SANTOS, M.V.F. et al. Aspectos agronômicos e bromatológicos de leguminosas forrageiras no nordeste brasileiro. Arch. Zootec., v.59, p.245254, 2010.

VERDECIA, D.M.; RAMIREZ, J.L.; LEONARD, I.; et al. Rendimiento y componentes del valor nutritivo del Panicum maximum cv. Tanzânia. Rev. Electrón. Vet., v.9, p.1-9, 2008.

VALLE, C.B.; TORRES, F.E.; LEMPP, B. Shearing strength and chemical composition in the selection for quality in Brachiaria brizantha. In: INTERNATIONAL GRASSLAND CONGRESS, 20., 2005, Dublin. Proceedings... Dublin: Wageningen Academic Publishers, 2005. p.102.

VAN SOEST, P.J.; ROBERTSON, J.B.; LEWIS, B.A. Symposium: methods for dietary fiber, neutral detergent fiber, and nonstarch polysaccharides in relation to animal nutrition. J. Dairy Sci., v.74, p.3583, 1994.

VAN SOEST, P.J.; ROBERTSON, J.B.; LEWIS, EB.A. Methods for dietary fiber, neutral detergent fiber, and nonstarch polysaccharides in relation to animal nutrition. J. Dairy Sci., v.74, p.3583-3597, 1991. 